\title{
The Success of Tomorrow Is Based on Actions of Today
}

\author{
PenttinenMika Ville Johannes ${ }^{a}$
}

\begin{abstract}
Success of the organization is only success so far without the appropriate competence. Therefore, the Finnish Defence Forces will also need professional and motivated individuals both now and in the future. The variable, interdependent, and complex environment has set totally new requirements for future's officers ${ }^{1}$. The Finnish cadets' selection process plays a crucial role, because the Finnish Defence Forces educate and train all the officers by itself. By means of the student selection will be made decisions whose influences have long temporal dimension. The officers who graduate from the Finnish National Defence University will build up the tomorrow's Finnish Defense Forces. In this paper, it will address the quality and functionality of the Finnish Defence University's student selection processes as part of competence and knowledge management from the organization's point of view ${ }^{2}$. Because of overall changes of society and the security environment, the Finnish officers' education and training system (see Figure 1) has been modified frequently during the few recent years. Both the reforms of the degree programs of Military Science and the Finnish higher education culture's modifications have been tried to notice during the analysis. The paper is based on the author's doctoral thesis that is compiling at the moment.
\end{abstract}

\section{Keywords}

Student selections, officers' education and training, degrees of Military Science

The external and the internal operating environments are changing all the time. That is why, it is necessary to evaluate the quality and functionality of the Finnish cadets' education and training system as well as the selection process. At the moment, the basic and the postgraduate degrees of Military Science are modifying. The renewed Cadet and the General Staff Officer Courses began in 2015. In addition, the degree of Master of Military Science will be updated since $2018^{3}$. Due to the education and training system modifications, the Finnish cadets' and postgraduate officers' selection processes are also in transition. For example, the closing date for applications of the renewed General Staff Officer Course was at the middle of August 2013. The entrance exam was hold at the beginning of April 2014 and the course started at the end of July 2015. On the other hand, re-defined applying requirements and selection scoring of the cadets have been brought into use this spring ${ }^{4}$.

The roots of all the evolutions of these days can be found from the beginning of the twenty-first century. The very first students enrolled in the degree programs of Bachelor of Military Science and Master of Military Science at the 88th Cadet Course in 2001. With the Bologna process, the Finnish National Defence University's degree reform polished into a

\footnotetext{
aThe Finnish National Defence University, Finland

Correspondent Author:

PenttinenMika Ville Johannes, the Finnish National Defence University, P.O.Box 7, FI-00861, Helsinki, Finland

E-mail: mika.penttinen@mil.fi
} 
few years. It reached the finished constitution in $2006^{5}$. The degree of Bachelor of Military Science consists of academic and military-professional studies. The objectives of the academic studies are to create ability to use scientific methods and capacity to work as an expert. The military-professional studies whereas produce vocational competence and necessary licenses related to officer profession. The degree of Bachelor of Military Science takes three years. After graduating, the young lieutenants have a mandatory four-year working period in the units before the two-year studies of the Master of Military Science. The pilots are an exception. They conduct their higher university degree straight after the bachelor-level studies ${ }^{6}$. The renewed degree of Bachelor of Military Science which enforced in autumn 2015 is naturally based on the current degree's structure. Consequently, the modifications are primarily revisions of the degree's contents and periodicity of the studies ${ }^{7}$.

\section{THE APPLICATION AND ACCEPTANCE PROCEDURE OF THE STUDIES OF BACHELOR OF MILITARY SCIENCE}

In the early twenty-first century, the application and acceptance procedure completely updated due to modification of the structure of the basic degrees of Military Science. The main principles of the students' selection process since 2001 have guided the detailed modifications of the application and acceptance procedure. The latest an important progress of the cadets' selection was the Finnish National Defence University's joining to the Finnish universities joint applying system in 2010. Consequently, the applying is made by means of the electric form via internet. However, some complementary information is asked by letter. The secondary-level education and the conscript training scores distributions have also readjusted regularly after 2001. The Finnish National Defence University selects students to the Cadet Courses excepting the pilots. The Air Force Academy carries out a separate pilots' selection annually ${ }^{8}$.

The main pre-requirements for the Finnish National Defence University in the Finnish universities joint applying system are:

(1) The Finnish nationality;

(2) The training and education of the reserve officer before the Cadet Course;

(3) The secondary-level or some other education, which qualifies to the academic studies;

(4) Appropriate state of health including mental balance and sufficient physical performance;

(5) B class driving license (at least the first phase conducted before the Cadet Course);

(6) Rightful lifestyle and suitability to officer's tasks in general;

(7) At the maximum 26-years old excluding college based (warrant) officers ${ }^{9}$.

If a candidate does not have the requisite education, he can request a special permission to take part in the Cadet Course's entrance exam. A statement about the adequate capability of the candidate for the studies of Bachelor of Military Science must supply to the Finnish National Defence University with the application form. The exceptions from the age limit or standard of general state of health are also possible. The reserve non-commissioned officers who have finally been accepted to the studies of Bachelor of Military Science have to conduct the Team Leader Course before the Cadet Course ${ }^{10}$.

The main selection criteria to the Cadet Course are leadership and management skills, motivation, academic capabilities as well as aptitude to the military education and training. Relevant features and competence have been measured by means of the certificates from the secondary-level education, conscript training and military service experience together with the entrance exam. The entrance exam comprises of aptitude, psychological, literature, and physical tests. Since 2015, the maximum selection score has been 170 points. In comparison with previously, the selection comprises two new sections 


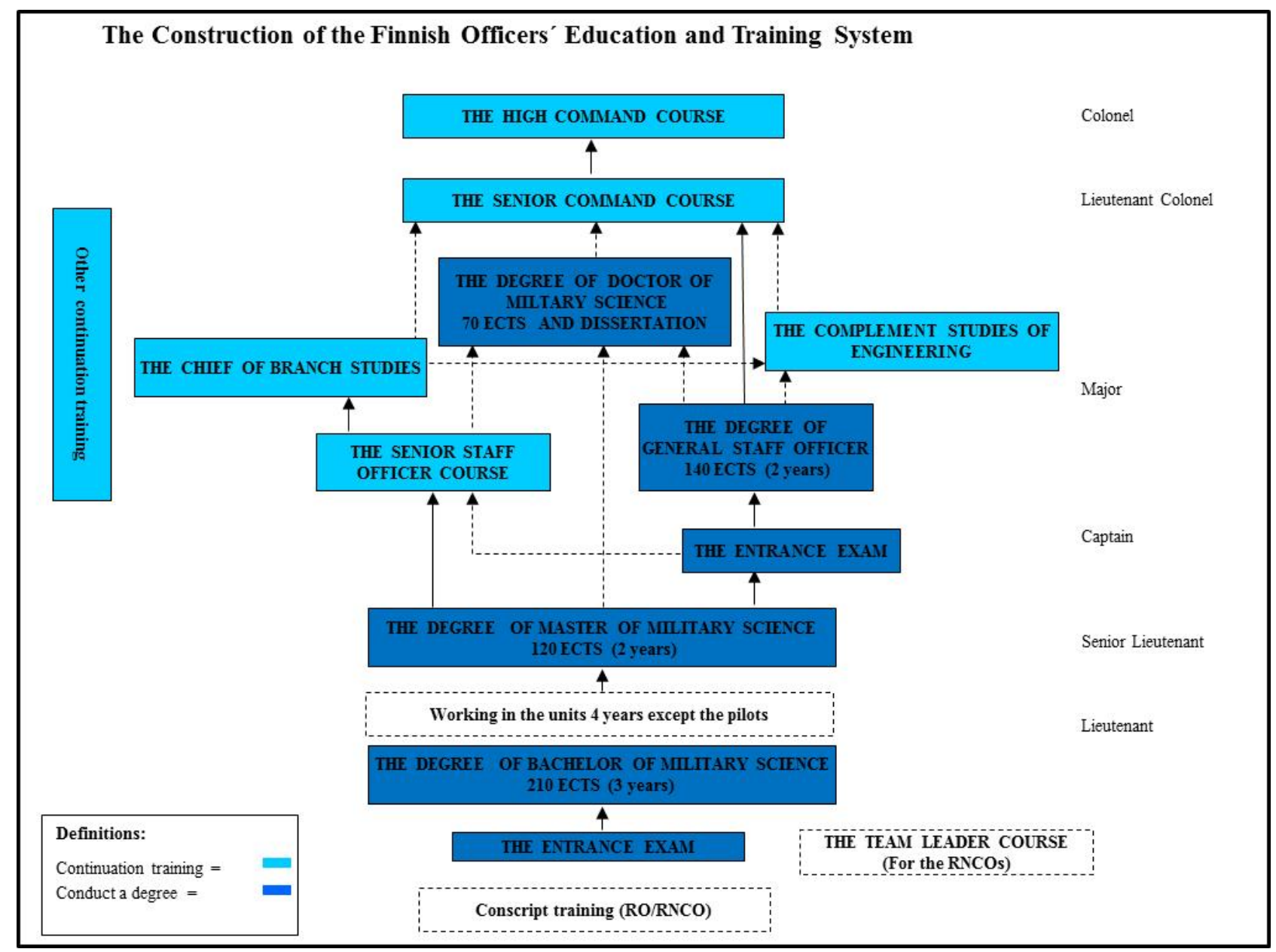

Figure 1. The Education and Training System of the Finnish Officers Is a Deliberate Tool for Competence and Knowledge Management From the Finnish Defence Force's Point of View ${ }^{11}$.

and the maximum score has been risen by five points. The added parts are the military service experience, whose score varies from zero to two points and the muscular strength test, whose score varies from zero to three points ${ }^{12}$.

The secondary-level education score varies from zero to 50 points depends on the examination and grades. For example, a matriculation examination can produce 50 points at its best. Instead, the vocational basic degree can only generate 30 points at the maximum. The military training and service experience scores together vary from zero to 37 among college based (warrant) officers, reserve officers, and reserve non-commissioned officers. Accordingly, the maximum points of the basic education and military training together with the service experience are $87^{13}$.

A pre-selection will be conducted based on the secondary-level education, military training, and military service experience points. Naturally, main pre-requirements have to be fulfilled also. Approximately 500 applicants have been accepted to participate in the entrance exam yearly ${ }^{14}$. Inadequate application forms have been the most significant reason to disqualification in the pre-selection from 2010 to 2014. Around $15 \%-25 \%$ of the candidates 
failed to supply an eligible electrical application form or to send the requisite attachments by mail in the every spring ${ }^{15}$.

All the applicants have to send photocopies of their military training's and military service experience's certificates as well as photocopies of their driving licenses. If the candidate has not conducted a matriculation examination, a photocopy of the secondary-level education's is demanded. Furthermore, applicant's personal request for a special permission to take part in the entrance exam has to supply in the case of deviation concerning the main pre-requisites. Some of candidates do not supply expected attachments at all, which is quite a certain sign about their lack of motivation to become an officer. Of course, a letter can disappear sometimes for instance on the way. Then, applicant has justice to ask from the Finnish National Defence University a permission to re-submit the application form and attachments. If the applicant fails to supply the requisite documents again, the case will be closed at the time ${ }^{16}$.

The entrance exam takes two days. It consists of comprehensive aptitude test (see Figure 2), essay writing, 12-minute running test, muscular strength test, medical examination, and feed-back. The evaluation of the aptitude score varies from zero to 50 points and a poor result of the evaluation means disqualification in the whole exam ${ }^{17}$.

The essay writing score varies from zero to 25 points, but a poor result of the examination is not a basis for disqualification in the whole exam. The 12-minute running test score varies from zero to five points. The result under the 2,600 meters means failing in the whole entrance exam while the result 3,000 meters or more gives five points. In addition, the muscular strength test score varies from zero to three points. All in all, the maximum of the entrance exam points is 83. A positive sample in the drug test, the inappropriate state of health and any deviations in the security clearance are also basis for disqualification ${ }^{18}$.

The DefenceCommand determines the size of the Cadet Course yearly. In accordance with the needs of the Finnish Defence Forces, the number of admissions is limited. Annually, around 135 students will be accepted immediately in the Cadet Course in the Finnish universities joint applying system. The fact is that some of them do not receive their places in the Cadet Course. As a result, the Finnish National Defence University nominates pretty many accessory candidates to the studies of Bachelor of Military Science ${ }^{19}$.

However, the insufficient amount of selecting score has been the most common reason to fail among those applicants who has accepted to participate in the entrance exam from 2010 to 2014. Approximately $15 \%-20 \%$ of the candidates who have taken part in the entrance exam have not been admitted to the Cadet Course or nominated to the accessory candidates' waiting list. On the other hand, around $10 \%$ of those applicants who has accepted to participate in the entrance exam will never arrive at the exam at all $^{20}$.

During the last few years, the 12-minute running test has caused the major part of eliminations in the case of the single tests. Five percent to 10 percent (5\%-10\%) of the male and $55 \%-85 \%$ of the female have run under the 2,600 meters annually. The quite a big tolerance of the females' results can partly be explained by means of the amount of the female applicants. Every single running result has a prominent effect among the females. In the course of time, the 12-minute running test has been become almost an equal obstacle in comparison with the insufficient amount of selecting score. Due to some kind of deviations in the security clearance, $2 \%-10 \%$ of the candidates who have taken part in the entrance exam have been rejected. For all that, the security clearance is not basis for disqualification for good. Consequently, a candidate who has behaved has been able to apply again and begin studies in the Cadet Course later on. On account of the requirements of the 


\begin{tabular}{|l|c|c|c|c|c|}
\hline \multicolumn{1}{|c|}{ FEATURES } & $\begin{array}{c}\text { Motivation and } \\
\text { valuation } \\
\text { THE NATURE } \\
\text { OF THE TESTS }\end{array}$ & $\begin{array}{c}\text { Learning } \\
\text { capabilities }\end{array}$ & $\begin{array}{c}\text { Emotional } \\
\text { balance }\end{array}$ & Leadership & Management \\
\hline Direct tests & - & $\mathrm{x}$ & $\mathrm{x}$ & $\mathrm{x}$ & $\mathrm{x}$ \\
\hline Suggestive tests & $\mathrm{x}$ & - & $\mathrm{x}$ & $\mathrm{x}$ & $\mathrm{x}$ \\
\hline Indirect tests & $\mathrm{x}$ & $\mathrm{x}$ & - & $\mathrm{x}$ & $\mathrm{x}$ \\
\hline
\end{tabular}

Figure 2. There Are Five Main Features or Capabilities, Which Have Been Measured by the Comprehensive Aptitude Test in the Finnish Cadets' Application and Acceptance Procedure. All Features or Capacities Are Evaluated by Numerous Methods ${ }^{21}$.

sufficient state of health, those form quite a dense silo among the applicants who in the first instance want to the navy. Nevertheless, the appropriate state of health including mental balance and sufficient physical performance is invariably guaranteed already over the conscript training. Besides, there has not been any positive sample in the drug test in the entrance exam from 2010 to $2014^{22}$.

By means of both the entrance exam and the pre-selection, applicants are ranked. The candidates can apply for a few various options in the every service. If two applicants have exactly equal selection scores, the points of the entrance exam will be dominant selection criteria. If it is still necessary to separate the equal candidates, the military training points will be primary before the secondary-level education and military service experience points ${ }^{23}$.

The 97th and the 98th Cadet Courses are the first two, which have been selected by means of the Finnish universities joint applying system. The 97th Cadet Course was selected in 2010 and its students graduated at the end of August 2013. Those young lieutenants have ahead of them a mandatory four-year working period in the units before they can continue studies in the Master of Military Science program from 2017 to 2019. In 2010, there were 591 applicants. The average selection score among them who started studies was 91.7 points of the maximum of 165 . The 98th Cadet Course selected in 2011 and its students graduated at the end of August 2014 as the lieutenants and Bachelors of Military Science also. In 2011, there were 608 applicants. The average selection score among them who started studies was 94.9 points of the maximum of 165 . After graduating, those young lieutenants will also have a mandatory four-year working period in the units before the two-year studies of Master of Military Science will begin in $2018^{24}$.

\section{FROM THE PAST TO THE TRAILBLAZER}

The students of the 88th Cadet Course were selected in 2001. At that time, applicants applied for the degree of Bachelor of Military Science or the degree of Master of Military Science. Conducting the higher university degree took a little over three and half years. Thus, the Masters of Military Science graduated at the beginning of June in $2005^{25}$.

The selection process was quite a similar to the present practice. The total maximum of the selection 
score was 148 points, consisting of the secondary-level education and the military training points together with the entrance exam points. The secondary-level education score varied from zero to 50 points. Despite the same amount of total points, the internal emphasis of the secondary-level education score differs from current. Furthermore, the military training score varied from zero to 48 at that time. All in all, the range of the secondary-level education and military training points varied from zero to $98^{26}$.

The entrance exam consisted of a comprehensive aptitude evaluation and a 12-minute running test. The aptitude evaluation score varied from zero to 50 points and a poor result of the evaluation meant disqualification. The 12-minute running test was not scored, but the result of the under 2,500 meters meant disqualification. All in all, the maximum score of the entrance exam was 50 points. Like nowadays, a positive sample in the drug test, inappropriate state of health and any deviations in the security clearance meant disqualification ${ }^{27}$.

In 2001, there were over 500 applicants to the Cadet Course and 135 of them were finally accepted to the studies of Master of Military Science. In general, the selection of the students of the 88th Cadet Course can be valued as successful. The fact is that from 135 accepted master-level students, 129 young officers graduated. The overall assessment comprises 28 laudable, 98 good and above the mark. Only three cadets' pro gradu theses were graded improbatur which mean that they did not graduate in $2005^{28}$.

However, it is worth noting that the final evaluation of the selection's quality can be determined by examining each of the 88th Cadet Course officers individually from. Moreover, it is necessary to compare both the course's curriculum and objectives to the final grading of Master of Military Science. On the other hand, because the Masters of Military Science of the 88th Cadet Course have been able to apply to the 58th General Staff Officer Course, it is necessary to survey the results of the 58th General
Staff Officer Course's application and acceptance procedure as well. Before this kind of evaluation has been done, it is impossible to declare a reliable judgment or assessment of the quality of the students' selection process as a whole ${ }^{29}$.

The closing date for applications to the 58th General Staff Officer Course was at the middle of August 2013. The entrance exam was hold at the beginning of April 2014 and the course started in July 2015. Approximately 150 officers from the 88th and elder Cadet Courses have applied to the 58th General Staff Officer Course and around 75 of them were eventually accepted. It means that all in all one of third of officers is carried out the degree of the General Staff Officer ${ }^{30}$.

In accordance with the needs of the Finnish Defence Forces, the number of admissions was limited. The main selection criteria were leadership skills and commander features, analytic capabilities, operational thinking, planning and execution abilities together with scientific abilities. Relevant features and capabilities were measured by both the certificates from the Cadet Course and a general language proficiency test, officers' annual physical and field action competence tests, a medical certification and a security clearance. In addition, applicants were asked to supply references (an independent evaluation of his or her personal capacity to serve in the Finnish Defence Forces' higher posts after the course) written by the applicant's superior, the unit and the service headquarter. Together with the above mentioned certificates and references the selection process included a comprehensive aptitude evaluation and the entrance exam ${ }^{31}$.

The acceptance to participate in the entrance exam was conducted by means of a pre-selection which based on the aptitude evaluation, the requisite certificates, and references. A result under the middle-level in the general language proficiency test, inappropriate state of health, low physical or field action competence, the negative references, a poor 
result in the aptitude evaluation and possible deviations in the security clearance meant automatic disqualification ${ }^{32}$.

The 58th General Staff Officer Course's entrance exam consisted of four modules, which were based on certain military subjects and research methodology. Each of the modules has its own emphasis, which was taken into account in the final scoring. The knowledge of the leadership, strategy, military history, tactic and operational art, military pedagogy, military engineering and military logistic together with research methodology was tested in several applied tests. The objective of the entrance exam was to measure the ability to learn and study successfully in the General Staff Officer Course. The final acceptance to the 58th General Staff Officer Course was completely based on the entrance exam score ratings ${ }^{33}$.

\section{THE PROFOUND THESIS IS NEEDED}

\section{Fact or Fiction}

So far, the studies and reports concerning the Finnish cadets' application and acceptance procedure are mainly based on quantitative methods and have viewed the correlation between selection phase performance, academic achievement and success at the first tasks as a young officer. For example, in the thesis from the year 2009 "Upseerivalinnoista upseerinuralle-Pääsykoe- ja opintomenestyksen yhteys työssä menestymiseen lyhyellä aikavälillä” (ad lib translation "From the Officer Selections to the Officer's Career-The Entrance Exam and the Study Success Connection to Working Life in the Short Term") examines the short-term connection between the individuals results of the entrance exam in 2002 with their study success and the performance in the working life ${ }^{34}$. The thesis is a clear continuation to the validity research about the aptitude test as the part of cadets' selection process from the year 2004. The validity research certified that the comprehensive aptitude test has an unquestionable connection to the academic achievement at the Finnish National Defence University. On the other hand, the separate parts of the aptitude test betoken reliably certain feature or capabilities, which are graded at the Cadet Course $^{35}$.

Although the clear connection between the performances in the entrance exam with the academic achievements has been found as well as second-year performance assessment in the working life, the validity of the prognosis in the long term is inevitably limited. The sample is small and the temporal dimension is quite a short. In general, the academic achievement in the officers' education and training and the working life performance assessment are not so simple factors because of many interpretive issues as well as potential intervening and uncontrollable variables. It is clear that to increase the reliability of the research results, there should be continued exploration with a larger sample and longer temporal dimension by means of methodological triangulation.

On the other hand, a doctoral dissertation in which the Finnish officer clausewitzical strategic abilities are reviewed by means of the Myers-Briggs type indicator-based classification represents the qualitative research methods about the subject. The research presents rather strongly that in nowadays, suitable people are not selected to the Finnish National Defence University. The dissertation challenges the Finnish National Defence University to a self-critical review by claiming that cadets' and young officers' academic and strategic capabilities are weaker than among the civilian university-level students. In the dissertation, the poor performance appeared to be largely the result of the Finnish Defence Forces' own activities and the Finnish Defence Forces are seeming to be an organization without strategic know-how ${ }^{36}$. However, the researcher himself has said that his dissertation is an opening about the subject and some of the affirmations of the research could not be 
certified entirely ${ }^{37}$. It can be said that in any circumstances, the basis for the dissertation is slightly quivocal considering it ought to be both reliable and reproducible.

As from above can be noted research about the Finnish National Defence University's student selection process is heterogeneous, but unfortunately very limited also. The conducted researches offer conflicting visions, which each have both supporters and opponents. Without exception and regardless of the final results of the studies and surveys, they all have recognized the need to explore the phenomena by the varied methods and longer temporal dimension in order to reliably estimate the quality of the Finnish National Defence University's student selection system. Attempts for bringing the different views closer together is probably unnecessary just for the scale of the matter. However, several independent reviews comprising parallel interpretations are necessary to widen the field.

\section{The Interpretative Approach Allows the Multidimensional Review}

It will be essential to determine if there is a connection between the success in the Cadet Course's entrance exam, academic achievement and the admissions to the General Staff Officer Course. In other words, is it possible to recognize the most appropriate individuals for the Finnish Defence Forces' higher posts already in the selection phase of the Cadet Course? In addition, the short-term connection between success in the entrance exam and later on in studies has to be surveyed still in the future.

The profound review of the cadets' selection process connected with a single officer age group from the Cadet Course selection to the General Staff Officer's Course selection is a prerequisite for both a long-term and qualitative research. This kind of perspective helps to estimate the phenomena and the factors which play a crucial role in the selection of the officers. Due to modifications of the structures of the degrees of Military Science, it will be relevant to assess the strength of the cause-and-effect relations between separate competences. With the help of this kind of research, it will possible to identify the challenges which depend on the general development of Finnish society or the actions of the Finnish Defence Forces.

Obviously, the phenomena can be studied by means of the three separate and previously mentioned Cadet Courses. The students of the 88th Cadet Course are the both the very first Masters of Military Science and pioneers at the renewed General Staff Officer Course in 2015. On the other hand, the 97th and the 98th Cadet Courses were the first two, which have been selected by means of the Finnish universities joint applying system ${ }^{38}$.

The 88th, 97th, and 98th Cadet Courses give genuine option to structure the Finnish officers' selection process as part of competence and knowledge management and reflect its relationship to military and social factors. At the same time, it can evaluate the quality and functionality of the selection criteria from the Finnish Defence Forces' point of view.

\section{CONCLUSIONS}

The previous researches and practical experience from the last decade have been certified the good functionality of the Finnish cadets' selection process. However, without exception and regardless of the final results of the independent studies and surveys, they all have recognized the need to explore the phenomena by the varied methods and longer temporal dimension in order to reliably estimate the quality of the Finnish National Defence University's student selection system. Quite a narrow but heterogeneous field of the scientific knowledge about the functionality and quality of the Finnish cadets' selection process sets the need to execute the multidimensional and profound researches about the 
subject. All in all, several independent reviews comprising parallel interpretations are necessary to widen the field, because at present, it is impossible to evaluate the long-term success of the officers' selection process from the Finnish Defence Forces' point of view. The possible challenges must be identified and at the same time find out whether they occur in the recruitment phase or if the problem is the selection process in itself.

The success of tomorrow is based on actions of today. It can be noted that the all kind of student selections are always concerned with the values and interests of the executive organization, because who would not want to get the most talented students to educational institutions. However, concerning the cadets' application and acceptance procedure, it should be take account of particularly. The decisions which will be made in the selection process extend over several decades and impact through the work of future officers.

Although many things have changed and established totally new challenges to officers, it is still valid that the good officer must have a cool head, clean hands, and a warm heart. After all, in this instance, the case is simple: to scout out far the best-while honoring traditions and facing the future. It is necessary to interpret both the selection process and the underlying factors, when developing the quality and functionality of the selection system of the basic and postgraduate degrees of Military Science as part of competence and knowledge management.

Closer co-operation than ever before between the Finnish universities and society sets totally new challenges to the Finnish National Defence University. As for the cadets' selection process, the specific eligibility prerequisites of the applicants should be noted at full length. On the other hand, one of the most important requirements for candidates is the training and education of the reserve officer-either gained directly in the conscript training or in the case of reserve non-commissioned officers at the Team
Leader Course - is also both a real challenge and a great possibility.

The conscript training undoubtedly enables a unique option compared with other universities to recruit and select the most suitable applicants to the Finnish National Defence University. To put it briefly, the first step in the successful selection process of the Finnish officers is ability to provide the excellent reserve officer and reserve non-commissioned officer training and education. The rest depends on the quality of the officers' selection as well as the education and training which is carried out by the Finnish National Defence University.

\section{Notes}

1. DefenceCommand (2005a), p. 5 and p. 7.

2. Compare DefenceCommand (2004).

3. Liimatta and Myyryläinen (2012), pp. 16-20, the Finnish National Defence University (2013a) and (2014a). Compare Vaahtolammi (2013), pp. 78-79 and p. 95.

4. Rosti (2014) as well as the Finnish National Defence University (2013a), (2013d), and (2015a). Compare Vaahtolammi, p. 79 and p. 95.

5. The Finnish National Defence University (2006) as well as Vaahtolammi, pp. 62-67 and pp. 70-73.

6. The decree about the Finnish National Defence University (1124/2008), 4§-11§ as well as the Finnish National Defence University (2013b), pp. 39-42, (2013f), pp. 6-7 and (2014c), pp. 6-7.

7. The Finnish National Defence University (2015b).

8. DefenceCommand (2013), pp. 7-8 and Vuorinen (2009). Compare the Finnish National Defence University (2001), (2009), (2013f), and (2014c).

9. DefenceCommand (2013), pp. 6-7, the Finnish National Defence University (2014c), pp. 20-21 as well as the law about the Finnish National Defence University (1121/2008), $16 \S, 19 \S$, and $30 \S$.

10. DefenceCommand (2013), pp. 6-8, the Finnish National Defence University (2014c), pp. 20-21 as well as the law about the Finnish National Defence University (1121/2008), $16 \S$ and $19 \S$.

11. The Finnish National Defence University (2015a).

12. The Finnish National Defence University (2013e) and (2014b).

13. The Finnish National Defence University (2014b).

14. The Finnish National Defence University (2014b) and (2014c), p. 24. Compare DefenceCommand (2013), p. 8 
and the law about the Finnish National Defence University (1121/2008), $14 \S$.

15. Rosti and the Finnish National Defence University (2015a).

16. DefenceCommand (2013), pp. 7-8, Rosti and the Finnish National Defence University (2014c), p. 23.

17. The Finnish National Defence University (2014b) as well as (2014c), pp. 24-25 and p. 28.

18. The Finnish National Defence University (2014b) as well as (2014c), p. 21 and p. 28.

19. Rosti and the Finnish National Defence University (2015a).

20. Rosti and the Finnish National Defence University (2015a).

21. Kulomäki and Nyman (2004), p. 11, Nyman (2011), and the Finnish National Defence University (2015a).

22. Rosti and the Finnish National Defence University (2015a).

23. DefenceCommand (2013), p. 10 and the Finnish National Defence University (2014c), p. 28.

24. The Finnish National Defence University (2015a).

25. The Finnish National Defence University (2001).

26. The Finnish National Defence University (2001). Compare the Finnish National Defence University (2009), (2010), (2013e), and (2014b).

27. DefenceCommand (2002), DefenceCommand (2005b), and the Finnish National Defence University (2001). The Application Procedure for the Officers' Academic Education and Training Program at the Finnish National Defence University in 2001 states that the 12-minute running test limit was 2,500 meters with both genders. On the other hand, based on DefenceCommand's documents, the 12-minute running test's qualification limits were different with men and women during some years at the beginning of 2000s and for example, the separated limits (men 2,500 meters and women 2,300 meters) had been used at the entrance exam in 2002.

28. The Finnish National Defence University (2005) and (2015a).

29. The Finnish National Defence University (2013a).

30. The Finnish National Defence University (2013c) and (2013d).

31. DefenceCommand (2013), pp. 14-18, the Finnish National Defence University (2013a) as well as the law about the Finnish National Defence University (1121/2008), 17§, 18§, and $19 \S$.

32. DefenceCommand (2013), pp. 14-18, the Finnish National Defence University (2013a) and the law about the Finnish National Defence University (1121/2008), 17§. Compare Liimatta and Myyryläinen, pp. 16-20.

33. DefenceCommand (2013), pp. 16-18 as well as the Finnish National Defence University (2013a) and (2013d). Compare the law about the Finnish National Defence University (1121/2008), 17§.

34. Salonen (2009).
35. Kulomäki and Nyman.

36. Aalto (2012), pp. 301-316.

37. Aalto University (2012). Based on researcher's statement at his doctoral dissertation event at the 26th of April 2012 (Aalto: The Strategist's Tragedy-The Finnish Officers as a Clausewitzian Strategists).

38. The Finnish National Defence University (2001), (2009), (2010), and (2013a) as well as Vuorinen.

\section{References}

Aalto University. 2012. The Doctoral Dissertation Event of the Mika Aalto (The Strategist's Tragedy-The Finnish Officers as a Clausewitzian Strategists) at the 26th of April 2012.

Aalto. 2012. "The Strategist's Tragedy—The Finnish Officers as a Clausewitzian Strategists.” Doctoral dissertations. Aalto University Publication Series. Helsinki: Unigrafia Oy.

DefenceCommand. 2002. The Selection of the Students to the Officer's Academic Education and Training Program (ID PAK A 01:03.02.13). Defence Force's Archives Management System (DFAMS).

— 2004. Defence Forces Personnel's Competence and Knowledge Development Strategy. (ID R387/5.1/D/III/26.1.2004). Defence Force's Archives Management System (DFAMS).

- 2005a. Defence Forces Human Resources Strategy. Helsinki: Edita Prima Oy.

- 2005b. The Rising of the 12-Minute Running Test's Rejection Limits in the Officers' Academic Education and Tarining Program's Entrance Exam (ID111/5.2/D/I 1.12.2005). Defence Force's Archives Management System (DFAMS).

- 2013. PVHSM 072 the Application and Acceptance Procedure of the Degrees of Military Science. (ID HJ110/24.1.2013). Defence Force's Archives Management System (DFAMS).

Kulomäki and Nyman. 2004. The Validity Research of the Officer Selections' Aptitude Assessment 2003. Defence Force's Education and Training Development Center, Publication Series B/1/2004. Helsinki: Edita Prima Oy.

Liimatta and Myyryläinen. 2012. "The Genaral Staff Officer Degree Will Be Renewed-Are You Ready?” The Finnish Officers’ Military Magazine, December. Mikkeli: Printing Fellows AO-Paino.

Nyman. 2011. Presentation at the Cadets Selection's Arrangement Meeting in 2011. The Chief of Branch at the Department of Action Competence.

Rosti. 2014. Personal Statement at the 11th of August 2014. The Chief of Recruitment and Selection Branch at the Department of Academic Affairs. 
Salonen. 2009. "From the Officer Selections to the Officer's Career-The Entrance Exam and the Study Success Connection to Working Life in the Short Term.” The General Staff Officer Degree's Thesis, the Finnish National Defence University, Helsinki.

The Decree About the Finnish National Defence University (1124/2008). 2008. Retrieved March 14, 2015 (http://www.finlex.fi/fi/laki/smur/2008/20081124).

The Finnish National Defence University. 2001. The Application Procedure for the Officers' Academic Education and Training Program at the Finnish National Defence University in 2001. (ID R482/5.1/D/II1.2.2001). Defence Force's Archives Management System (DFAMS).

- 2005. The Summary Reprort of the 88th Cadet Course's Studies. (ID R384/5.3/D/I/13.6.2005). Defence Force's Archives Management System (DFAMS).

- 2006. The Summary Reprort of the Reform of the Degrees of Military Science. (ID AC23176/1.12.2006). Defence Force's Archives Management System (DFAMS).

- 2009. The Guide for Applicants for the Degree of Bachelor of Military Science and the Degree of Master of Military Science in 2010. Helsinki: Edita Prima Oy.

—. 2010. The Guide for Applicants for the Degree of Bachelor of Military Science and the Degree of Master of Military Science in 2011. Helsinki: Edita Prima Oy.

- 2013a. The Application Procedure for the 58th General Staff Officer Course. (ID AJ2096/1.2.2013). Defence Force's Archives Management System (DFAMS).

—. 2013b. Study Guide 2013. Common Part: The 100th Cadet Course, the Degrees of Master of Military Science, the 66th Senior Staff Officer Course. Tampere: Juvenes Print Oy.

- 2013c. The Pre-selection for the 58th General Staff Officer Course's Entrance Exam. (ID AJ16895/23.8.2013). Defence Force's Archives Management System (DFAMS).

- 2013d. The Execution of the 58th General Staff Officer Course's Entrance Exam 7.-11.4.2014. (ID AJ16623/2.9.2013). Defence Force's Archives Management System (DFAMS).
- 2013e. The Detailed Selection Requirements for the 101st Cadet Course. (ID AJ19283/29.10.2013). Defence Force's Archives Management System (DFAMS).

- 2013f. The Guide for Applicants for the Degree of Bachelor of Military Science and the Degree of Master of Military Science in 2014. Helsinki: Juvenes Print.

- 2014a. The Education and Training Programs of the Basic Degrees of Military Science. (ID AK12656/25.6.2014). Defence Force's Archives Management System (DFAMS).

- 2014b. The Detailed Selection Requirements for the 102nd Cadet Course. (ID AK23651/24.11.2014). Defence Force's Archives Management System (DFAMS).

—. 2014c. The Guide for Applicants for the Degree of Bachelor of Military Science and the Degree of Master of Military Science in 2015. Helsinki: Juvenes Print.

- 2015a. The Department of Academic Affairs, the Electric Archives 2001-2015. Defence Force's Archives Management System (DFAMS).

—. 2015b. The Department of Academic Affairs, the Conference About the Reform of the Degree of Bachelor of Military Science on February 12, 2015.

The Law About the Finnish National Defence University (1121/2008). 2008. Retrieved March 14, 2015 (www.finlex.fi/fi/laki/smur/2008/20081121).

Vaahtolammi. 2013. The Finnish National Defence University's 20-years Anniversary-The First Steps of the Military University in 1993-2013. Tampere: Juvenes Print.

Vuorinen. 2009. Conversation About the Finnish National Defence University's Joining to the Finnish Universities Joint Applying System. The Record of the Meeting at the 23rd of August 2009, the Ministry of Education.

\section{Bio}

PenttinenMika Ville Johannes, MA in military science, captain, the Finnish National Defence University; research fields: leadership and management. 